\title{
Minimising tax on writing fees and royalties
}

\author{
C R SANDISON
}

Many doctors in general or private practice receive fees in addition to those earnings from other related sources such as lecturing or writing. In most cases they find that their total earnings from all these sources are added together in their accounts for the year concerned and an overall amount of expenditure is claimed against income to give a net profit for the year-on which tax is paid. These profits are, in fact, assessed under what is known as Case II Schedule D, and tax is normally paid on the so-called preceding year basis-in other words, what you earn this year you pay tax on next year.

Those with no Schedule D income from general or private practice, but who nevertheless have earnings as fees or royalties from their writing activities, may find considerable difficulty in obtaining an adequate expense allowance against that particular income when negotiating with HM Inspector of Taxes. Furthermore, if only royalty income is received, they may well find that this is not taxed under Case II of Schedule D but under Case VI and additionally, that where larger amounts of royalty income are received they may be subject to investment income surcharge-which, for those already paying higher rates of tax, makes the net return derisory.

The most important principle to establish with the Inland Revenue when you begin writing is that you are in business as an author, whether or not these activities are successful. In other words, considerable expenditure may be incurred writing a book or series of articles even though these may never be published, and in these circumstances a quite justifiable loss may be incurred which could be set against other income-for that particular tax year. The Inland Revenue's attitude to authorship is to a certain extent clouded by the fact that in the past they have had claims made by those whose authorship was more that of a hobby than a professional activity. One example is a case where a man bought a house on the edge of a Scottish loch which he retired to for several months of the year to fish; he argued that he required the peace and tranquillity of the area to give him inspiration towards his unsuccessful writing activities. But he could hardly expect the Inland Revenue to allow him to set the costs of running that particular croft, travelling, and other expenses against his other income on the basis of authorship losses. Nevertheless, a doctor who had spent a considerable amount of time and money carrying out research for a particular book, and in this connection had travelled extensively throughout the United Kingdom and abroad, incurring secretarial and other writing costs, could, without doubt, establish himself as an author even though the book ultimately produced little in the way of royalties.

Other criteria which the Inland Revenue would use towards the establishment of authorship status would be (a) high income from royalties and fees in comparison to other earnings; $(b)$ a substantial proportion of one's professional time spent on such activities; (c) continuity of "production," and thus income. In this particular case, if one book were written against which expenses were claimed initially and thereafter royalties trickled on over a number of years until a new book was produced, the Revenue might well rescind the authorship status and assess that royalty income as unearned income under Case VI of Schedule D, simply on the basis that no expense was incurred in the earning of those royalties. Thus they are by implication unearned income.

C R SANDISON, FCA

\section{Allowable costs}

Once authorship status has been established, all costs incurred in connection with writing may be charged against the income. These costs will normally consist of the following:

Writing materials and so on-Any costs such as stationery, printing, paper, pencils, and other incidentals used directly in the writing of articles are allowed in full.

Secretarial costs-These are allowed in full for a secretary who has been employed to type articles. Many secretaries do this sort of job in their spare time for a modest fee and doctors paying such sums should advise their secretaries that this income must be declared on their income tax returns. Doctors often use their own wives for secretarial work and any amounts paid to them may be claimed in exactly the same way. A rate of $£ 2$ an hour for this would be reasonable and a doctor's wife can at present earn up to $£ 17.50$ a week before any National Insurance becomes payable, and just under $£ 19$ a week before any tax is due.

Assistance fees-There are occasions when a colleague may help to prepare an article and be paid a fee. This is an allowable deduction.

Use of home and rented rooms-A study at home is often used for writing and the costs incurred may be claimed in full. The normal procedure is to calculate the percentage of the area of the house used for this purpose and to take that proportion of total household expenses as a charge against taxable income. In a house with eight main rooms of which one is used exclusively for professional writing, for instance, a claim may be made for one-eighth of the cost of rates, rent (if any), insurance, heating and lighting, repairs and renewals (both internal and external), and domestic help. In addition, the full cost of all fixtures and fittings in the room is allowable in the year in which they are bought. This would normally include carpets, curtains, desks, chairs, light fittings, filing cabinets, heating equipment, and so on.

Capital equipment-In addition to the fixtures and fittings mentioned above, a doctor is likely to buy such items as a typewriter and a calculator, particularly if the secretarial work is being done from his own home. The cost of these is allowed in full in the year in which the item is bought, as are all other items of equipment used in connection with writing activities.

Telephone and postage-A proportion of one's telephone bill is chargeable for calls made in connection with writing. This is particularly relevant where a lot of research has to be carried out and when detailed conversations with colleagues take place over the telephone. Conversations may also take place with publishers. Postage for these purposes is also allowable. While it is difficult to be precise about the proportion of one's total telephone bill that is allowable (since this obviously depends on the amount of writing done during the year) I have found that most Inspectors of Taxes are willing to accept a reasonable charge for this item.

Professional books and magazines-The cost of reference books and magazines bought for research for writing articles is allowable in full. This may include journals taken regularly, even though not every issue is likely to contain material relevant to the particular line of research being carried out.

Professional costs-If an accountant is employed to prepare accounts and agree them with the Inland Revenue, the cost of his services may be claimed. Similarly, other professional fees such as lawyers' fees incurred in connection with literary earnings may be claimed. 


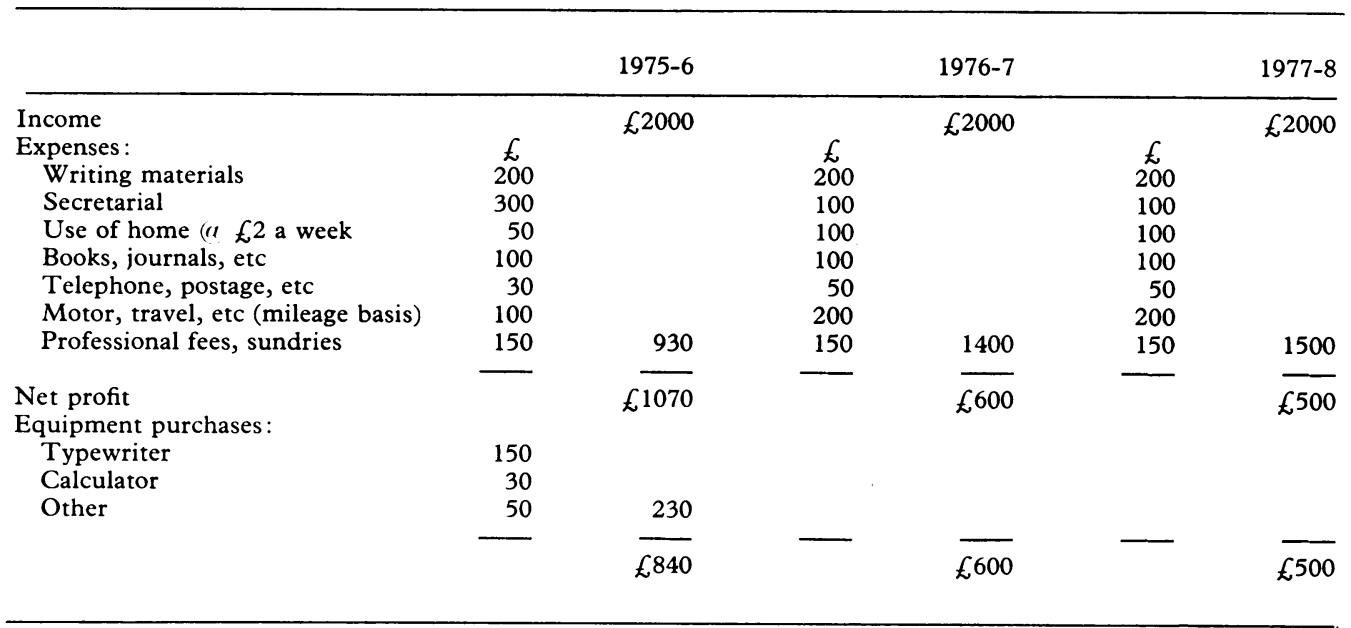

Tax payable:

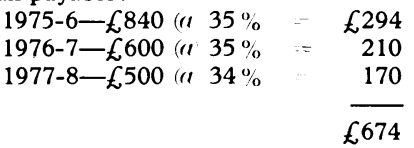

Motor and travel expenses-It may be necessary to do a great deal of travelling in order to compile material for writing articles or books. The whole of this cost may be claimed, and car expenses are dealt with either on a mileage basis or as a percentage of total motoring costs. Thus if a doctor travelled 2000 miles carrying out research into a series of articles, he would probably find that he gained the greatest tax advantage by charging this at the appropriate AA rate for his car. If this was $12 p$ a mile, a total claim of $£ 240$ could be made in that particular year.

When a new book is being written, many of the costs mentioned above may be incurred in the years before publication, and special rules apply to give relief for this expenditure against such things as the sale of copyrights or lump sums received on publication in advance of royalties. The rules are that when the book has taken more than 12 months but under two years to prepare, the lump sum payment may be spread back over two years of assessment, and if more than two years has been required for the preparation, the income may be spread back over three years. If, for instance, a doctor received $£ 6000$ for the sale of a copyright on 1 April 1978, and he began the book in the autumn of 1975, he would have taken some two and a half years to prepare the work. The gross income would then be spread back as follows:

$$
\begin{array}{rr}
\text { Year of assessment } & 1975 / 76 \\
1976 / 77 & £ 2000 \\
1977 / 78 & £ 2000 \\
& £ 2000
\end{array}
$$

The appropriate expenses incurred in those three years could then be charged against this income before arriving at the net assessable profit. These rules also apply where there are joint authors and, furthermore, are extended where the lump sum royalties are paid during the first two years after publication. Thereafter, unless a new edition is published, the problem will normally arise as explained above where royalties are reduced to a trickle and where expenses are minimal. To avoid this income then being assessed under Case VI of Schedule D, and possibly as unearned, the rule relating to continuity of production must be foremost in the mind of the author. This will probably include writing another publication altogether as it is not always practical to bring out a new edition of the same book (perhaps after only three years of initial publication).

There are cases where doctors may not assign a copyright until 10 years or more after first publication. Where this is the case, and an assignment or the granting of an interest is given for a period of at least two years, payment of any lump sum received thereon may be spread over the lesser of six years or the duration of the grant or licence.

The table shows how by spreading this income and claiming the appropriate expenses which have been incurred the overall taxation may be considerably reduced:

It is essential that, whatever your personal circumstances may be, if anything more than minimum fees are received from writing activities you should take professional advice.
WORDS The Latin calx, calcis has some interesting medical derivations; it means pebble, stone, or limestone, whence we have CALCIUM, CALCAREOUS, CALCIFICATION, and CHALK (the second $c$ in calcis was pronounced $\mathrm{k}$ ). CALCULUS, a little stone, is the diminutive of calx and is applied to concretions occurring in the body-for instance, gall bladder and urinary tract. Little stones were used by the Romans for reckoning on the counting-board or abacus, whence we have calculus also as a branch of mathematics, and CALCULATE, to compute mathematically, to opine (American usage). Incidentally, "concretion" has nothing to do with $\mathrm{L}$ creta, chalk. It derives from $\mathrm{L}$ con cresco (past participle cretum), grow together. "Concrete" stems from this root. Calculus in dentistry is a concretion precipitated on to the surface of teeth from the saliva. An older term for dental calculus, still used, is TARTAR. The word tartar was originally used to describe the hard crust forming on the sides of wine casks during fermentation, whence by analogy it was adopted by dentists (1806). On analysis the deposit on wine casks proved to be the potassium hydrogen salt of an organic acid, which was consequently named TARTARIC. The same KH salt, known as CREAM OF TARTAR, was formerly used as a laxative. Calx, calcis, meaning heel in Latin, is of different origin from calx, pebble, and gives us OS CALCIS and CALCANEUM, the heel bone, and L calcar, spur, whence CALCARINE cortex and fissure, and no connexion, of course, with calcarious. In Roman times a soldier's shoe was caliga, from calx, a heel. The diminutive of this word, caligula, a little soldier's shoe, was a nickname given in his boyhood to Gaius Caesar. Considering his later behaviour as emperor, could this perhaps have been the soldiers' way of calling him a "little heel ?" 